\title{
A Estruturação de Dissertações e Teses em Administração: Caracterização Teórica e Sugestões Práticas
}

\author{
Pedro Lincoln Mattos
}

\section{Resumo}

Os conflitos do que se identifica como opções metodológicas na estruturação de produtos acadêmicos, especialmente dissertações e teses, têm, a um tempo, revelado e acentuado a necessidade de se buscar um sentido maior que oriente aquele trabalho e não o deixe exposto ao sério risco de perder-se no formalismo. Este parece uma ameaça, tanto mais quanto metodologias se porfiam na busca mais adequada de representação do real. Qual o sentido daqueles produtos acadêmicos? Este ensaio propõe, como alternativa preferível, que se adote o próprio sentido pragmático deles, caracterizado-os como ações comunicativas assertivas, uma retórica racional argumentativa, conceito aristotélico reelaborado por Perelman e Olbrechts-Tyteca. Põe-se em contraste, portanto, a análise hermenêutica do discurso com o paradigma epistemológico do conhecimento moderno. À discussão teórica seguem-se, na parte final, sugestões práticas de como poderiam estruturar-se dissertações, teses e mesmo artigos acadêmicos, geralmente também elaborados com sentido assertivo em comunicação à comunidade científica.

Palavras-chaves: teses e dissertações; retórica argumentativa; formalismo; metodologia de pesquisa.

\section{Abstract}

The conflicts of what is identified as methodological options on the structuring of academic products, particularly dissertations and theses, have, at a time, reveled and stressed the necessity of a search for a higher meaning which can guide that work and prevent it from the serious risk of falling lost in formalism. Formalism is a threat, as much as methodologies strive and compete in search of a better representation of reality. Which is the meaning of those academic products? This essay holds to be a preferable alternative the adoption of their pragmatic meaning itself, so taking them as assertive, communicative actions and argumentative, rational rhetoric, which is an Aristotelian concept re-elaborated by Perelman and Olbrechts-Tyteca. Hermeneutic discourse analysis is, therefore, set in contrast with epistemological paradigm of modern knowledge. In the final part, theoretical discussion is followed by practical suggestions on how dissertations, theses and even academic papers could be structured, as they are also generally addressed to scientific community in an assertive way.

Key words: dissertations and theses; argumentative rhetoric; formalism; research methodology. 


\section{Motivação, Objetivo e Estrutura deste Ensaio}

A preocupação metodológica tem polarizado, desnecessariamente, as atenções e aflições de estudantes de pós-graduação entre nós, em prejuízo da motivação maior pelo conhecimento válido, da relevância de temas e resultados, e, provavelmente, dos prazos, hoje ainda muito longos, de conclusão de seu trabalho. Para o mestrando e, muitas vezes, o doutorando, o problema maior das teses e dissertações seria, então, de natureza técnica. Estruturas, estratégias e técnicas de coleta e análise de dados, logicamente conectadas a opções metodológicas, e estas, finalmente, a paradigmas formam o mundo rígido, a teia em que se vêm enredados os iniciantes, e cujos detalhes podem estar a povoar seus pesadelos. Não há só o risco de a engenharia da ciência fazer sombra aos conteúdos da construção contextualizada do conhecimento, inibida por procedimentos-padrão. Há, mais grave, o de formar a crença de que a prática científica é, sobretudo, uma prática de regras metodológicas.

Em que consiste a estruturação de uma dissertação, de uma tese? Esta, a pergunta-objetivo. Sem dúvida, procedimentos-padrão aperfeiçoados são valores da lide científica. Contudo, em movimento sutil, certamente devedor ao paradigma moderno de ciência que privilegia o empírico e a verificação, toma vulto a objetivação do dado e do conceito (construtos, variáveis). Isso dá ao processo de pesquisa caráter prático e multiplicativo, mas facilmente deixa para trás a verdadeira questão da construção de conhecimento, que é a do critério, o porquê das escolhas de pesquisa. A prática de estruturações lógicas e a habilidade no manuseio de técnicas desenvolvem o mundo metodológico da forma em prejuízo da discussão do critério. O formalismo é essa hipertrofia do valor forma. No labor científico, ele é fonte de estereótipos e sumidouro da riqueza dos significados.

Tal é a motivação deste ensaio, que aponta o conflito - pretensamente redutível a opções metodológicas - na estruturação de trabalhos científicos, especialmente teses e dissertações, como sinal da necessidade de imprimir a esses textos um sentido maior que não os deixe expostos ao sério risco de perderem-se no formalismo. Hoje, o que de melhor se faz é tratá-los como relatórios de pesquisa, como se tais documentos não encerrassem intencionalidades e escolhas cruciais, e que, portanto, seu elemento diferenciador fossem as estratégias metodológicas. Este artigo propõe, como alternativa preferível, que o sentido maior daqueles produtos seja seu próprio sentido pragmático, caracterizando-os como ações comunicativas assertivas, atos de fala estruturados como retórica racional argumentativa, conceito aristotélico reelaborado por Perelman e Olbrechts-Tyteca 
(1999). De certo modo, portanto, põe-se em contraste a análise hermenêutica do discurso com o paradigma epistemológico do conhecimento moderno em face da realidade. À discussão teórica seguem-se, na parte final, sugestões práticas de como poderiam estruturar-se, ao longo de uma dinâmica quase individualizada, dissertações, teses e mesmo artigos acadêmicos, geralmente elaborados e propostos com sentido assertivo em comunicação à comunidade científica.

\section{Firmando uma Ótica de Análise}

\section{De Conflitos Metodológicos e Epistemológicos à Abordagem Lingüística}

Que há no detalhe das tais opções metodológicas? Um lugar comum diz, não sem algum eufemismo, que ali se tem apenas diferença de óticas quantitativa e qualitativa na metodologia de pesquisa. Como a conciliar dicotomia insustentável, acorre alguém para propor procedimentos multimétodo, ou, de forma coloquial, uma metodologia quali-quanti... Neste caso, uma prática de composição de técnicas resolveria o problema, principalmente se, entre elas, a diferença for posta em termos de produzir números, por processos padronizados, ou produzir descrições, por processos lingüisticamente mais livres. De tal operação, sobra, no entanto, algo mal justificado na metodologia, subentendida como questão de ótica e preferência pessoal.

Acadêmicos mais competentes elevam o debate: por trás das diferenças metodológicas se esconderiam apenas legítimos (ainda que irreconciliáveis) paradigmas epistemológicos. Nesse sentido, tornaram-se antológicas as (simétricas) taxionomias de Burrell e Morgan (1979) e de Deetz (apud Alvesson e Deetz, 1999), ou, com maior sensibilidade ao ponto de vista filosófico, a de Guba e Lincoln (1994). E, então, a depender de paradigmas epistemológicos definidos por oposição uns aos outros, a discussão metodológica dificilmente deixará de ser caudatária de abordagem dicotômica, como parecem sugerir manuais clássicos (Babbie, 1979; Miles e Huberman, 1984; Barzun e Graff, 1992; Denzin e Lincoln, 1994).

Recorrendo à tradição cultural que, no Ocidente, tem trabalhado a possibilidade e as condições do saber, é sustentável a posição de que a discussão acima permanece dentro das fronteiras do paradigma epistemológico moderno (século XVIII - século XX), pois ali a disputa é pelo método em que o conhecimento melhor traduz uma realidade objetiva a todos, admitindo-se ou não, como elemento diferenciador, certa interferência do sujeito nesse processo. Por tal método, o conhe- 
cimento científico poderia ser afirmado com propriedade sobre as coisas. Ele expressaria traços estáveis, de alcance generalizante, à moda de leis (conhecimento nomotético), mesmo que depois viesse a mudar e completar-se constantemente.

A afirmação da atividade lingüística e comunicativa no centro da questão epistemológica, ou, antes, a própria desimportância da questão ontológico-epistemológica, é típica da consciência filosófica pós-metafísica (Habermas, 1990) ou pós-moderna (Rorty, 1994). Aqui a discussão está completamente reformulada. Fala-se dos significados gerados na comunicação humana, e a concepção moderna de objetivação do conhecimento é um deles, de grande importância histórico-cultural, sem dúvida, mas com status epistêmico completamente diferente daquele que ela própria se atribui.

Assim, embora seja possível, sem muita dificuldade, identificar um conflito epistemológico entre textos de diferentes procedências metodológicas, o problema da estruturação de teses, dissertações e artigos acadêmicos poderia, por princípio, ser definido a partir de contexto lingüístico-comunicativo de construção de conhecimento. Sua natureza, fecundidade e versatilidade serão discutidas adiante.

Em que consistiria a mudança de perspectiva? Focar o que fazem as pessoas ao se expressarem de determinada forma nas práticas e instituições acadêmicas; focar o jogo de linguagem e a lógica discursiva que então praticam, antes que o conteúdo lógico do discurso e os procedimentos que têm tradicionalmente cercado sua demonstração. Esta última orientação na estruturação de dissertações e teses tem conduzido à exposição inoportuna de conflito metodológico, circunscrito a um paradigma de conhecimento, que confunde o estudante. Haveria, pois, vantagem se o sentido pragmático e não o semântico daqueles atos de fala presidisse a estruturação deles.

\section{Na Administração: o Dilema entre Metodologias Inclusivas e Objetivadas}

Voltemos, ainda, ao conflito metodológico e epistemológico, no que tem a ver com a pesquisa em administração, para, em seguida, lançar sobre ele uma visão fora do paradigma moderno. Afinal, é a partir daquele conflito que tem sido encarada a estruturação de teses, dissertações e artigos acadêmicos.

Caiu com traços de impasse no campo de estudos de administração de organizações o que as ciências sociais, no século XX, conheceram como um dilema epistemológico: interpretar seus objetos de interesse (geralmente as pessoas) de um ponto de vista, de certo modo, interno a eles (inclusivo) ou fazê-lo de um 
ponto de vista externo a eles (objetivado), partindo-se aqui da idéia de Guba e $\operatorname{Lincoln}(1999)^{(1)}$.

Nas metodologias inclusivas, o analista, procurando o significado, tem de se valer de todos os recursos da linguagem humana, especialmente os analógicos, e tecer ilimitados contextos de uso para os conceitos-chaves de sua interpretação, tentando reduzir inesgotável imprecisão. Nas metodologias objetivadas, o observador, pondo diante de si o objeto, se exclui da cena, e a precisão se impõe porque o conhecimento se ordena à identificação de tendências nos fatos e ao controle ou uso do objeto, via previsão e generalização. Nisto se assemelham ciências sociais às naturais e tecnológicas. Com a precisão, vem a mensuração e todos os recursos conceituais desenvolvidos pela matemática aplicada. As análises estatísticas são o ponto favorito de chegada da metodologia aqui chamada de objetivada.

Mas que se note: a terminologia inclusiva e objetivada não é apenas nova versão do binômio qualitativa e quantitativa. Primeiro, porque envolve dois significados independentes, referentes à demarche epistemológica do conhecimento, e, segundo, porque foge a um paralelismo (quantitativo-qualitativo) que é inadequado, posto que a quantidade também é uma das muitas qualidades do objeto (ou seja, qualitativo envolveria todas as qualidades, até mesmo as quantitativas).

A administração, como disciplina, tem recorrido aos dois pontos de vista, pois lhe convém tanto entender o ponto de vista das pessoas, aproximando sujeito (pesquisador) e objeto (pessoas), quanto adotar a ótica organizacional e macrodecisória. O ingresso massivo de textos científicos no campo da administração, inspirados nas metodologias desenvolvidas por antropólogos desde meados do século passado, mostra que a gestão organizacional tem que entender o significado dos comportamentos e das culturas. Não lhe basta produzir modelos estruturais. Por outro lado, a orientação da administração para decisões e contextos estratégicos leva-a à produção de interpretações de amplo espectro que falem de estruturas sociais mais amplas: mercados, redes organizacionais, governos, economias, fluxos financeiros, sistemas estruturados, modelos decisórios etc. Não se pode negar que a ação racional, sobretudo se instrumental, impõe certa organização simplificada da realidade.

Contudo, por que a bipolaridade dos pontos de vista? Por que não poderia, simultaneamente, incorporar outros? O que se critica está justamente em insistir na simetria bipolar, produzindo restrição, artificialidade e conflito. Em nome de quê? Da lógica! Traem-se aí os fundamentos epistemológicos do positivismo lógico: a produção de significado válido deve ser sempre um movimento de raciona- 
lidade lógica (aliás, a administração moderna tem lá suas raízes: basta rever a administração científica de Taylor e Fayol).

Guba e Lincoln (1994, p. 116), após comentarem a questão dos dilemas metodológicos, sugerem que as polaridades permanecerão por uma questão de diversidade de paradigmas, “aguardando o surgimento de um metaparadigma que tornasse irrelevante a diferença entre os paradigmas anteriores”. Todavia, por falta de uma superestrutura lógica (o metaparadigma) não é justo restringir a concepção metodológica - de fato, cingindo-se aquele argumento ao próprio paradigma do positivismo lógico! A complexidade, que é própria também da administração, tem como uma de suas características teóricas ser dialógica, ou seja, envolver a coexistência de duas ou mais lógicas (Morin, 1996).

Do ponto de vista da pragmática da linguagem, será suficiente justificar o contexto adotado, e, caso a caso, ajustar a ele os procedimentos de demonstração. De fato, todo discurso - no sentido habermasiano, distinto da ação comunicativa ordinária - se ordena por seu contexto social comunicativo, e dele tira suas regras de estruturação metodológica (Wittgenstein, 1996). A seção seguinte tenta caracterizar tal contexto, um uso específico de linguagem, no caso de teses, dissertações e artigos acadêmicos.

\section{Teses, Dissertações, Artigos Acadêmicos: De Que se Trata?}

Sobre nosso objeto de estudo, cumpre, por primeiro, perguntar: De que se trata? Que contexto social o constrói? A resposta, que conduz ao meio profissional acadêmico e a algumas de suas práticas mais características, determina também sua pertinência ao mundo das comunicações humanas ordinárias.

\section{Contra o Discurso de Intencionalidade Dúbia e de Volta às Coisas Simples}

Quem se desprende do sentido comunicativo de seu texto finda prendendo-se a como elaborá-lo e a seu caráter pragmático de legitimação ou afirmação pessoal perante o grupo social de referência. E a produção acadêmica fica exposta ao risco de tornar-se, sem embargo de seus méritos, principalmente uma demonstração de habilidade pessoal.

A lógica da demonstração de habilidade leva à sofisticação crescente, mas seu risco é prestar-se a um enclausuramento da comunidade acadêmica que a cultiva e, muitas vezes, à perda de relevância social. As dissertações e teses, 
momentos altos da vida e produção acadêmica sentem-se, para angústia de seus autores, na obrigação de ostentar especialmente aquelas qualidades de sofisticação formal e complexidade literária. Aí, porém, ter-se-á perdido seu sentido original. Resulta para os textos uma intencionalidade mal definida ou a dissociação entre forma e natureza do ato comunicativo. Ao tomarem-se certas dissertações e, principalmente, artigos acadêmicos, cabem às vezes as perguntas: Que quer realmente o autor? Que é toda esta cesta de elementos teóricos e empíricos? Uma bela demonstração de competência acadêmica?

As seções abaixo, no centro deste artigo, procuram a intencionalidade básica desses textos, tentando um caminho de volta às coisas simples!

\section{Atos Comunicativos}

Na seção 1, acima, afirmou-se que uma dissertação ou tese não deve ser caracterizada como um relatório ou registro solitário de pesquisa, sem embargo de que tais peças constituem sua base fundamental. É um ato lingüístico de comunicação, praticado na comunidade científica! Este ato de comunicação se firma sobre uma investigação feita, seja empírica ou não. Talvez mesmo tal investigação, a pesquisa, o preceda na ordem das preocupações práticas. Mas ele existe para além dela, que poderia acontecer em outro contexto (como seria o de um serviço, por exemplo), caracterizando, ao longo de todo o sentido semântico que enche sua(s) centena(s) de páginas, sentidos ilocucionários e perlocucionários (Austin, 1990) específicos. É preciso, preliminarmente, insistir nessa caracterização que pode produzir direção e coerência, daí para frente, dentro da enorme ambigüidade que tem marcado o perfil textual e metodológico das nossas dissertações e teses. Seus autores, e de muitos dos nossos artigos acadêmicos, não deveriam parecer, em certos momentos cruciais do texto, como em solilóquios!

Habermas (1989, p. 39) caracteriza o sentido interpretativo e reconstrutivo das ciências sociais e, analisando radicalmente toda expressão humana significante, diz: “toda expressão dotada de sentido - seja um proferimento (verbal ou não verbal), um artefato qualquer como, por exemplo, um utensílio ou um documento - pode ser identificada, numa perspectiva bifocal, tanto como uma ocorrência observável, quanto como a objetivação inteligível de um significado”.

E, logo adiante, referindo-se ao uso de linguagem, reporta-se a distinção importante:

"Ou bem a gente diz o que é o caso ou o que não é o caso ou bem a gente diz algo para outrem, de tal modo que ele compreenda o que é dito. Só o segundo modo de uso lingüístico está interna ou conceitualmente ligado às condições da comunicação. Dizer como as coisas se comportam 
não depende necessariamente de uma espécie de comunicação realmente efetuada ou pelo menos imaginada; não é preciso fazer nenhum enunciado, isto é, realizar um ato de fala” (Habermas, 1989, p. 40, grifo no original).

Cabe tratar como radicalmente distintivo em relação a outras formas de uso da linguagem, o conceito de comunicação válida, a comunicação que visa ao entendimento (não no sentido de conciliação, mas de compreensão e reconhecimento de um proferimento como válido, seja ele favorável ou desfavorável ao ouvinte). Distingue-se ele especialmente do agir estratégico por meio dos atos de fala, quando há, da parte do falante, um sentido perlocucionário de levar o ouvinte a algo que não passa pelo entendimento mútuo. São, para Habermas, dois modos incompatíveis de uso da fala que, no segundo caso, é apenas meio de transmissão de outro telos (intencionalidade) em relação ao ouvinte. Explica ele:

"O entendimento funciona da seguinte maneira: os participantes unem-se através da validade pretendida de suas ações de fala, ou tomam em consideração os dissensos constatados. Através das ações de fala são levantadas pretensões de validade criticáveis, as quais apontam para um reconhecimento intersubjetivo. [...] $\mathrm{O}$ agir comunicativo distingue-se, pois, do estratégico, uma vez que a coordenação bem sucedida da ação não está apoiada na racionalidade teleológica dos planos individuais de ação, mas na força racionalmente motivadora de atos de entendimento, portanto, numa racionalidade que se manifesta nas condições requeridas para um acordo obtido comunicativamente” (Habermas, 1990, p. 72).

Assim, a compreensão, à luz da teoria habermasiana, de teses, dissertações e artigos propostos aos pares, como atos racionais de comunicação na academia, afastaria dois tipos de estruturação: (1) a pura descrição de objetos e resultados de investigações pessoais, válidos apenas por qualidades formais e metodológicas; (2) a superformalização do texto, tido, então, como instrumento para produzir boa impressão ou legitimação pessoal no grupo.

\section{Atos Denotativos e Assertivos}

As dissertações e teses em administração, como em outras tradições acadêmicas, são proferimentos denotativos, os "que afirmam a verdade de" (Quine, 1960, p.13), que encerram a intenção de falar das coisas com propriedade. Sua pragmática é colocar quem os emite na posição de quem se supõe sabendo e o ouvinte na posição de quem deve dar ou recusar assentimento, sendo então tratado o enunciado proferido de tal forma que identifique e expresse claramente $o$ de que trata (Lyotard, 1997). Não pertencem ao “jogo de linguagem” (no sentido 
de ação lingüística, de Wittgenstein [1996, p. 30, 35]) da narrativa ou descrição literária, proferimentos estes que não acarretam a obrigação da justificação ao ouvinte, mesmo sendo o grande gênero do conhecimento ordinário (Lyotard, 1997).

Usando a categorização de Austin (1990), dissertações e teses são atos ilocucionários (pela intenção que imprimem ao proferimento) assertivos.

“A finalidade dos atos ilocucionários assertivos é comprometer o ouvinte com a verdade da proposição. É apresentar a proposição como um representante de um estado de coisas no mundo. [...] Toda assertiva é expressão de uma crença. O teste mais simples para identificar as assertivas é perguntar se o proferimento pode ser literalmente verdadeiro ou falso. Uma vez que as assertivas têm a direção do ajuste palavra-mundo, elas podem ser verdadeiras ou falsas” (Searle, 2000, p. 137).

A produção literária científica, de resto, é um tipo de proferimento denotativo.

“O conhecimento científico requer que um único jogo de linguagem, a denotação, seja mantido, excluídos todos os demais. O valor-verdade do enunciado é o critério que determina sua aceitabilidade. Claro, encontramos outras classes de enunciados, como os interrogativos ('Como podemos explicar que...?') ou prescritivos ('Tome-se uma série finita de elementos...'). Mas eles estão presentes apenas como pontos de inflexão (turning points) na argumentação dialética, que tem que acabar em um enunciado denotativo" (Lyotard, 1997, p. 25).

O conceito de denotação se acomoda, portanto, dentro do de assertividade, compondo-se os dois para prosseguir na caracterização lingüística de teses, dissertações. Essa caracterização é feita com o intuito de resgatar um sentido simples e original e, portanto, a unidade lingüística que não pode perder-se na multidão dos procedimentos metodológicos. A definição metodológica vem muito depois e não deve ameaçar estes primeiros traços - tão simples e lógicos - do tipo de ato de linguagem social de que fazem parte teses, dissertações e mesmo artigos que a elas se assemelham, submetidos à discussão da comunidade acadêmica. O que vitima boa parte desses textos é permanecerem como espécie de exercícios escolares.

É também para preservar o sentido denotativo e assertivo do discurso dissertatório que em seção posterior se sugere a primeira pergunta estruturante: Que tem você a afirmar sobre seu objeto de interesse?

\section{Discursos de Retórica Argumentativa}

Teses e dissertações são peças lingüísticas típicas das instituições científicas 
ocidentais. São rituais de entrada e de maturidade nas "comunidades de praticantes da arte” (Kuhn). Cabe perguntar agora pelo sentido perlocucionário desses atos de fala, pelo tipo de jogo de linguagem que costuma expressar aquelas relações sociais.

Seguindo uma longa tradição, os praticantes da ciência criam um contexto de arena de idéias e enunciados, e seus proferimentos tomam o grande sentido perlocucionário de retórica argumentativa, para o qual mobilizam enorme arsenal de estratégias metodológicas, em que se tornam especialistas.

Disso trata toda esta seção, avançando algumas estruturas lógicas essenciais à retórica argumentativa. Toma-se por base o hoje clássico trabalho de Chaïm Perelman e sua colaboradora Lucie Olbrechts-Tyteca, Tratado da Argumentação: A Nova Retórica, que, em sucessivas edições (1958, 1988, 1992, em francês, e 1996, 1999, já em português), vem influenciando, há quase 50 anos, os mais diversos meios científicos envolvidos com o conhecimento e a linguagem.

Cabe, de entrada, distinguir no entendimento do termo retórica, um sentido primitivo e um segundo sentido, que guarda certos elementos estruturais daquele, mas muda outros. A retórica antiga era o ato de falar de público, geralmente perante uma multidão, de modo persuasivo, visando a ganhar a adesão dos espíritos (Perelman e Olbrechts-Tyteca, 1999). Platão e outros identificaram um desvio desta arte no discurso dos sofistas, persuasivo e eivado de argumentos ad hoc, chamando-o de erística. No conceito posterior de retórica, que Perelman e Olbrechts-Tyteca (1952) em outra obra procuram recuperar, a partir da noção de conhecimento racional dialético em Aristóteles, a convicção é diferenciada da simples persuasão. O discurso convincente é aquele que deveria (é ordenado para) obter a adesão de pessoas racionais e capazes, honestamente postas em discussão. Isso determina estratégia argumentativa diferente, que os autores chamaram de nova retórica. É neste segundo sentido que o termo retórica é aqui usado, quer se explicite tal sentido acrescentando o adjetivo argumentativa, quer não. Coincidentemente, é esse tipo de comunicação que Habermas chama de Discurso (Diskurs), e que significaria "discurso organizado argumentativamente e numa intenção polêmica” (vide Nota Preliminar do Tradutor em Habermas [1989, p. 7-10]).

As teses, inclusive as de disputas por cátedras, e as dissertações são lugares tradicionais da arte argumentativa para fazer avançar o conhecimento, e como tal devem ser mantidas. Isso implicará, no entanto, recuperar o conceito de retórica e ajustar os desenvolvimentos técnicos daqueles discursos ao seu sentido argumentativo maior. 


\section{Da Idéia Cartesiana de Evidência, de Volta à Dialética de Aristóteles}

Quando Aristóteles, no Organon, resumindo a tradição grega de conhecimento elaborado, fez a distinção entre o raciocínio analítico e o dialético, estava pondo um extraordinário divisor de águas para dois tipos de conhecimento racional, daí para frente. Segundo ele, o raciocínio dialético era aquele resultante da relação argumentativa de alguém com seu auditório e produzia conclusão verossímil e aceitável, enquanto o analítico, conclusão absolutamente verdadeira. Para ele, ainda, o uso da razão com pretensões a certeza se restringia à retidão da lógica, mas acabou inspirando séculos de racionalismo sob o fascínio da verdade indubitável. O conhecimento resultante da troca de argumentos entre pessoas comuns ou entre "homens ilustres e sábios" só poderia levar à verosimilhança. Era outro tipo de racionalidade, autônoma e diferente da primeira. Aristóteles não fez qualquer hierarquia entre os dois tipos de conhecimento racional, mas os que o seguiram, sim, em desprestígio para o segundo deles, a ponto de que seu produto, a opinio, recebesse sentido pejorativo em relação à scientia (Coelho apud Perelman e Olbrechts-Tyteca, 1999).

Herdamos, nós e toda a ciência moderna, a associação racionalista da idéia de evidência à de certeza definitiva. Descartes e Stuart Mill foram disso os grandes formuladores. A evidência produzida na dialética caía ao nível de conhecimento imperfeito. Dizem Perelman e Olbrechts-Tyteca (1999, p. 1-2):

“O campo da argumentação é o do verossímil, do plausível, do provável, na medida em que este último escapa às certezas do cálculo. Ora, a concepção claramente expressa por Descartes, na primeira parte do Discurso do Método, era a de considerar 'quase como falso tudo quanto era apenas verossímil'. Foi ele que, fazendo da evidência a marca da razão, não quis considerar racionais senão as demonstrações que, a partir de idéias claras e distintas, estendiam, mercê de provas apodíticas, a evidência dos axiomas a todos os teoremas. [...] O desacordo seria um sinal de erro. 'Todas as vezes que dois homens formulam sobre a mesma coisa um juízo contrário, é certo', diz Descartes, 'que um dos dois se engana. Há mais: nenhum deles possui a verdade; pois se um tivesse dela uma visão clara e nítida poderia expô-la a seu adversário, de tal modo que ela acabaria por forçar sua convicção’ (Descartes, Oeuvres, t. XI, p. 205-206)”.

Já para as ciências naturais e, sob seu paradigma, para toda a ciência moderna, é racional o que é conforme ao método científico experimental, sendo substituída, com o mesmo status de certeza, a evidência racional-dedutiva pela evidência racional-sensível. Perelman e Olbrechts-Tyteca (1999, p. 2, grifo no orginal) se referem a isso e citam Stuart Mill: 
"Para os partidários das ciências experimentais e indutivas, o que conta é menos a necessidade das proposições que sua verdade enquanto conformidade com os fatos. O empirista considera como prova não 'a força à qual o espírito cede e vê-se obrigado a ceder, mas aquela à qual deveria ceder, aquela que, impondo-se a ele, tornaria sua crença conforme ao fato' (J. S. Mill, Liv. III, cap. XXI, vol. II, p. 94)”.

Ora, na sua prática, os cientistas sociais vivem a racionalidade dialética, no sentido aristotélico. Ela constitui o clima e o limite de seus textos e afirmações em congressos, de suas avaliações e decisões em situações acadêmicas. A grande regra do jogo na academia é a discussão (“Há controvérsias...”, brinca-se, diante de afirmações peremptórias). Portanto, ao construírem-se teses e dissertações baseadas em uma concepção cartesiana de evidência e racionalidade, restaria algo de incongruente na prática dos acadêmicos.

O que, desde a segunda metade do século XX, cada vez mais aparece é que o conhecimento racional analítico (no conceito de Aristóteles) é uma alternativa declinante, dentro de um grande ambiente de conhecimento racional dialético (sempre no sentido aristotélico). Popper, grande herdeiro, no século XX, da tradição analítica, foi seu reformulador e crítico e deixou claro, já mais ao final de sua obra e respondendo à dúvida cética de seu amigo Russell, que o conhecimento preferível, não o certo, é o limite onde podemos chegar (Popper apud Schilpp, 1974). Ainda no século XX, quanto mais a sociologia da ciência, após Kuhn, investigava os processos e relacionamentos na construção do conhecimento científico (Knorr-Cetina, 1981), e quanto mais se consolidava o pluralismo, não apenas no ambiente da cultura (Geertz, 1999), mas nos fundamentos epistemológicos da ciência (Apel apud Demo, 1997), mais esta passou a ser estudada em sua retórica (Latour e Fabbri, 1977; Gross, 1996) ou como um tipo de retórica (Santos, 2000).

\section{O Auditório e a Busca do Acordo com Ele}

“Todo discurso se dirige a um auditório, sendo freqüente esquecer que se dá o mesmo com todo escrito. Enquanto o discurso é concebido em função direta do auditório, a ausência material de leitores pode levar o escritor a crer que está sozinho no mundo, conquanto, na verdade, seu texto seja sempre condicionado, consciente ou inconscientemente, por aqueles a quem pretende dirigir-se” (Perelman e Olbrechts-Tyteca, 1999, p. 7, sem grifo no orginal).

Enquanto apenas se estuda e pesquisa, quase sem compromisso, não há pressão por estruturar o discurso, no caso, o artigo, a tese ou dissertação. Mas, quando a 
situação de comunicação se coloca e se avizinha, surge a perspectiva do auditório, conhecido ou desconhecido, real ou imaginado, cujo acordo se procura. Ao escrever, o estudante ou pesquisador sentir-se-á quase em presença dos avaliadores, dos ouvintes em congresso, de seus pares, talvez simpáticos talvez críticos. Não conhece seus rostos, mas é capaz de imaginá-los como juízes, quer ouvintes quer leitores.

Em relação àquele tipo de textos, há tensão e dúvida constante entre "particularizar” o auditório e o objeto do “acordo”, e “universalizá-lo” (Perelman e Olbrechts-Tyteca, 1999, p. 34). "O auditório universal é constituído por cada qual a partir do que sabe de seus semelhantes, de modo a transcender as poucas oposições de que tem consciência” (Perelman e Olbrechts-Tyteca, 1999). O orador não pode arriscar-se a se mostrar estranho ou em confronto com a experiência imediata de seu auditório, se lhe propuser tese e argumentos muito particulares; terá dificuldade, inclusive de lidar com a heterogeneidade dele. Será preferível, então, generalizar seus conceitos e argumentos; no mínimo, não terá sua rejeição imediata. Não pode ser, no entanto, inespecífico. Ser-lhe-ão exigidas objetividade e relevância, para a adesão (Perelman e Olbrechts-Tyteca, 1999).

O auditório, que também imagina o objeto do acordo no início do discurso ou durante ele, não perdoa o orador que não circunscreve sua proposição, ou seja, o objeto do acordo. Torna-se praxe falar de objetivos, enfoque, opções metodológicas e limitações de escopo na estruturação das dissertações e teses, ou deixar claro o essencial disso em artigos acadêmicos.

Nas dificuldades e desencontros dessa situação é que as convenções (acordos tácitos) encontram espaço e podem degenerar em formalismo. Um auditório corporativo, onde as posições orador-auditório às vezes se invertem, pode sinalizar ao orador: "faça-me isso e isso, cumpra tais e tais regras e eu o deixarei terminar seu discurso, como se tivesse havido consenso entre nós". Outras vezes o auditório, por falta de convicções sobre objeto confuso, indulgencia o orador por estar também em situação semelhante. Há uma grande complexidade de relações acontecendo entre orador e auditório, quando fisicamente presentes, e todo um simbolismo na linguagem das justificativas daquele ou na das perguntas feitas por este.

\section{As Quase-Estratégias (Argumentos) para o Acordo}

Na verdade, não se distingue bem se o acordo entre auditório e orador é obtido em torno de proposições, teses, objetivos práticos ou se em torno dos argumentos para tal, motivo por que, seguindo Perelman, estes são chamados neste subtítulo de "quase-estratégias". Este autor, que trata a ambos como "objeto de acordo", 
agrupa-os em duas categorias: uma relativa ao real, a outra relativa ao preferível (Perelman e Olbrechts-Tyteca, 1999, p. 74).

Primeiro, os argumentos relativos ao real se referem a fatos e verdades, assim chamados porque os fatos se imporiam, terminando a discussão - o que em meios críticos hoje já não se admite - ou porque o foco estaria na verdade (interpretação) que eles revelam. Esta é a grande categoria de argumentos (ditos empíricos) nos trabalhos científicos: recorre-se à observação sistemática de fatos, seja ela experimental ou não, seja previamente estruturada, seja ajustandose ao seu próprio curso, ou, ainda, objetivada em números ou por meio de outro tipo de conceito. É o caso dos argumentos oriundos do que acima se chamou de metodologias inclusivas e objetivadas. De qualquer forma, a empiria ainda conserva status superior à teoria, e a mensuração à interpretação do simbolismo humano.

As verdades, geralmente como crenças teóricas, e os fatos (dados organizados) devem ser montados como argumentos em função de intenções e pontos de vista, de início claramente manifestos, se possível sob a forma de proposições ou de hipóteses. Infelizmente, algo que muitas vezes aí é desdenhado, expondo fraqueza insanável, é a contextualização do argumento empírico, seja quanto à origem dos fatos, seja quanto à adequação de sua forma ou algoritmo de organização (tratamento), em face da interpretação pretendida.

Mas, segundo, os argumentos relativos ao real também se referem a presunções.

“Além dos fatos e verdades, todos os auditórios admitem presunções. Estas também gozam de acordo universal; todavia, a adesão às presunções não é máxima, espera-se que seja reforçada, em dado momento, por outros elementos. [...] As presunções estão vinculadas, em cada caso particular, ao normal e ao verossímil. [...] Presume-se, até prova em contrário, que o normal é o que ocorrerá, ou ocorreu, ou melhor, que o normal é uma base com a qual podemos contar em nossos raciocínios. [...] Os fatos presumidos são, num dado momento, tratados como equivalentes a fatos observados, e podem servir, da mesma forma que eles, como premissa para argumentações. Isso, bem entendido, até que se ponha em discussão a presunção” (Perelman e Olbrechts-Tyteca, 1999, p. 79-83).

Valores partilhados, hierarquias de importância, presunções e crenças podem ser vistas como se reportando a premissas muito gerais, espécie de argumentos últimos, que Perelman chama de "lugares", retomando e desenvolvendo o conceito aristotélico semelhante de tópoi. “Aristóteles distinguia os 'lugares comuns', que podem servir indiferentemente em qualquer ciência e não dependem de ne- 
nhuma, e os 'lugares específicos', que são próprios, quer de uma ciência particular quer de um gênero oratório bem definido" (Perelman e Olbrechts-Tyteca, 1999, p. 94).

Mesmo os lugares comuns têm preferências. Há os lugares de quantidade (por exemplo: o maior número de bens é preferível ao menor, e o contrário para as deficiências) e outros preferidos, conforme as culturas: a singularidade (o fato de ser único) ou a não-singularidade, a oportunidade (próprio ao tempo e ao caso), a verdade (o que não leva ao engano), o raro e original, o irreparável e irreversível etc. Quanto aos lugares específicos, cabe lembrar que as peças acadêmicas trabalham, afinal, com os tópoi de sua comunidade de referência e auditórios universais (por exemplo: o recurso aos clássicos na área ou autores de escolas mais prestigiadas, a consistência conceitual e a perfeição da forma etc.), e quanto mais são eles do domínio explícito do pesquisador, mais bem sucedido tende este a ser.

Enfim, a construção de argumentos é uma arte criativa na estruturação dos produtos acadêmicos, e a metodologia está a serviço dela. A argumentação para obtenção do acordo é tão intrínseca à retórica acadêmica, que pode alcançar qualquer ponto do texto. É marcando essa característica essencial que em seção posterior se sugere a terceira pergunta estruturante: "Que evidências lhe convém aduzir para sua afirmação?”. Nesse sentido, a legitimação propiciada pela referência à tradição literária - geralmente disposta, como bloco textual, antes de evidências empíricas, no caso de pesquisas deste gênero - é também um argumento.

\section{A Caminho de uma Estruturação Não-Formal}

Posta, nas últimas seções, uma justificativa teórica, sugerem-se, a partir daqui, caminhos práticos para uma estruturação que não incentive o formalismo nas dissertações, teses e outros trabalhos acadêmicos.

\section{A Dinâmica Antes da Lógica}

Condição básica para isso, no entanto, é estar atento à dinâmica, mais do que à lógica daquela estruturação. Trata-se de pensar a obra por meio do que se passa com seu autor. Primeiro, porque há circunstâncias e caminhos diferentes, caso a caso, e a estrutura - do objetivo à técnica de análise dos dados - montase progressivamente, por aproximações sucessivas. O esboço de estrutu- 
ra de tais trabalhos deve poder reconstruir-se inúmeras vezes, ao longo de sua própria execução, porque o essencial é a unidade do discurso. Há fases pessoais (inclusive, muito comum, a de confusão total), que intervêm, até que apareça aquela unidade do projeto. E o que, em abordagem lógica, parece detalhe prático (como a dificuldade de acesso a fonte de dados), pode determinar mudança na estrutura argumentativa. Não é correto que, resistindo-se a fazê-lo, a dissertação ficará “valendo mesmo assim, graças à metodologia”... Ela não é um simples exercício escolar! Dela se espera conhecimento relevante, e não se reúne a academia, examinadores e avaliadores externos, para replicar a atividade pedagógica interna de cada programa ou disciplina.

\section{"Que Tem Você a Afirmar Sobre Seu Objeto de Interesse, e Para Quê?"}

Esta é a primeira pergunta estruturante, típica, mas não exclusiva da fase de elaboração. É incrível como as pessoas começam a (e às vezes mesmo acabam de) escrever, sem saber direito o que têm a dizer! Na distinção entre "ter que dizer" e "ter o que dizer sobre" está a questão e o primeiro divisor de águas! É preciso que o projeto denotativo e assertivo exista de alguma forma, antes que alguém esteja na obrigação institucional de mostrá-lo, no caso, apresentando tese ou dissertação.

Todo objeto de interesse surge, confusamente, da problematização de um campo, localizável no tempo e espaço, e quer seja prático (como fazer) quer teórico, identificável nos escritos ou preocupações de um grupo de pesquisadores. O interesse é um fato existencial, ocorre a alguém, exige algum envolvimento prévio e certa direção, originais e próprios, pelo menos no caso de teses, ou partilhados com um mentor. O autor é, primeiro, ator. Que o motiva a inquirir cabe perguntar - a formar expectativa, em algum momento percebida como não atendida, não respondida? O clima vivido em um grupo de pesquisa? A experiência prática daquele profissional? De qualquer forma, a pesquisa começará (ou não) quando o (futuro) autor for percebendo, individualmente e ao contrário de muita gente, mas que passa indiferentemente ao largo, uma discrepância entre expectativa e realidade, respostas versus fatos ou perspectiva deles. A problematização do campo, assim conceituada (Popper, 1975), crescerá, definir-se-á e prosseguirá ao longo de todo o trabalho como um de seus vetores. Essa é a dinâmica da coisa. Como se vê, uma dissertação, tese ou artigo não começa quando alguém traça, ou descobre traçado em um manual, um roteiro de pesquisa!

E agora: “que tem você a dizer sobre isso?”. Não importa que diga e refaça várias vezes sua resposta, que hesite e não tenha segurança; mas, a partir de 
agora, forma-se um auditório (real, imaginário, universal) diante do autor, a fazerlhe aquela mesma pergunta. Há uma intencionalidade, que começa confusa à procura de verbalização, mas é muito real: "para que você se apresenta a esse auditório?” (É só uma formalidade para obtenção de certo título acadêmico?). Todo o trabalho consiste em responder a isso e, em seguida, argumentar sobre sua resposta. Mas exigirá um trabalho mental organizado!

E estamos diante da questão dos “objetivos”! Ela tem vários aspectos.

Convencionalmente, em nossas dissertações, teses e outros textos acadêmicos, o objetivo responde à questão: “que você se propõe a fazer?”. Os objetivos, então, tendem a condensar as ações e respectivos produtos que integram o trabalho de pesquisa, e nisso podem tornar-se equívocos. Porque a expressão, às vezes, significa a ação formulada como um todo e seu produto final; mas, de repente, também ações ou etapas intermediárias ou de segunda ordem. É de praxe apresentar objetivo geral e objetivos específicos. Às vezes, aquele indica - como é necessário - a intenção maior que origina a tese, mas, em outras, é apenas uma formulação gramatical mais ampla dos próprios objetivos específicos, e que, por isso, torna esta expressão pleonástica. Além disso, quando alguém, focando apenas as ações, se propõe fazer uma pesquisa, produzir conhecimento (?), quase em exercício acadêmico, os objetivos são sempre do gênero: “identificar...”, “explicar...”, "testar...”, “analisar...” etc. Ora, até aí não se terá acrescentado muito, pois se tem, apenas, desdobramento conceitual do próprio ato de pesquisar. E o predicado adicionado àqueles verbos se referirá ao objeto da pesquisa. Como se vê, há formalismo na questão dos objetivos!

Em vez disso, é preciso defini-la a partir de uma concepção teórica mais ampla. O objetivo a declarar será, antes de tudo, o do próprio proferimento, e responderá à questão do ato perlocucionário de fala, a finalidade mesma da iniciativa de proferi-lo: "por que agora se põe você a propor isso, e, portanto, fazer toda a pesquisa, em apoio a tal? Que quer você com tudo isso?” - quer saber o auditório. Então, como elemento estruturante, tem-se primeiro a finalidade social (ou mesmo de uso) da proposta (“contribuir para...”, "esclarecer por que...”, "oferecer resposta/alternativa a...”, “mostrar que é (não é) necessário...”, “direcionar o debate para...", "propor um modelo que possibilite..." etc.). Trata-se simplesmente do(s) objetivo(s) da tese, dissertação ou artigo, finalidade, propósito de tais ações lingüísticas, motivação que as origina.

Em relação ao objetivo do discurso, que afinal mobiliza naquele momento orador e auditório, cabe não apenas explicitação, mas justificativa de relevância. A justificativa pode ou não se tornar seção autônoma no texto. Ela apresenta argumentos que firmam o ato perlocucionário, enquanto outros argumentos, depois, firmarão o ato ilocucionário. 
A assertividade das teses, dissertações e artigos é sua característica básica como ato ilocucionário. "Que tem você a afirmar?” - começou por estabelecer esta seção. A isso respondem as propostas ou as hipóteses, a depender da formulação do objetivo. O auditório precisa conhecê-las, de entrada, para, ao final, quando se completar o ato assertivo, posicionar-se a seu respeito.

E que pensar da pergunta de pesquisa? É como um truque mnemônico para o autor não esquecer a problematização e o objetivo resultante, ao longo do seu trabalho e, assim, manter o rumo da argumentação. Quando o discurso, porém, for proferido, ela já terá sido respondida, será apenas figura retórica.

Enfim, sobre a fase de elaboração, cabe observar: pergunta e resposta surgem ao mesmo tempo, porque são processos de envolvimento, não apenas lógicos. Ninguém faz uma pergunta, se já não está no rumo de uma resposta (Demo, 1995). Igualmente, o para que se diz não vem antes nem depois do o quê; influenciam-se, e podem mudar juntos.

\section{"Que Interpretações Conceituais Você Está Tomando de Partida?"}

O que se disse, logo acima, de pergunta e resposta, e de para que e o que se fala, vale de novo: o objeto de interesse e a interpretação dele crescem juntos, e isso se dá tanto na problematização do campo quanto na proposta ou afirmação central do discurso. Porque não há interpretação desarmada, visão sem ponto de vista e fato sem teoria (Barchelard, 1972; Chalmers, 1993).

Aí está envolvida uma decisão crucial de todo texto científico: a definição do foco. Não que seja indispensável um subtítulo assim, mas que sem formulação nítida do ângulo sob o qual se vê o objeto - constituindo-o neste mesmo ato não há discussão objetiva, nem, portanto, seu sentido como ato comunicativo, que é o entendimento. $\mathrm{O}$ foco interpretativo põe o discurso em um caminho, caracteriza o campo de estudo e define a área em que se situa uma tese ou dissertação, o que não se dá pelo objeto físico, fato social ou histórico. Normalmente, boa parte da assertiva já está posta com o enfoque. Sua justificativa estará na própria análise conceitual do objeto problematizado, e geralmente é organizada a partir de área ou subárea de estudos a que se prende.

É por isso que é preciso rever e explicitar, se possível de forma sistemática, a armação conceitual (teoria) que se está tomando por base na própria formulação e interpretação do problema. Isso pode ser feito em um só bloco textual, ou de outra forma. É delicada e exige competência a escolha articulada dessas fontes conceituais, situadas, obviamente, em determinada tradição de conhecimento de qualidade científica. Não se trata de um rol de citações ("fulano disse isso, cicra- 
no disse aquilo”...) originadas de uma pesquisa bibliográfica sem rumo seletivo. De novo, aqui, é fácil escorregar no formalismo, ao dar o passo indevido do objetivo ostentatório, o ato de fala estratégico, acima criticado, com base no conceito de ação comunicativa, de Habermas. Ao ler o engenhoso tecido de referências bibliográficas em que se constitui boa parte da produção acadêmica, pode ocorrer a alguém a suspeita irreverente: "Será a revisão de literatura o ópio da academia?”.

Há duas outras finalidades importantes na revisão de teoria, de fato, dois argumentos-padrão em apoio ao proferimento assertivo: (1) a conceituação usada se sustenta como um todo lógico, integrado; (2) ela é conhecimento intersubjetivamente provado e aceito (argumento de autoridade). Junto com estes argumentos vem a legitimação do discurso.

Nesse sentido argumentativo se entenderia a expressão convencional fundamentação teórica. Infelizmente, é comum vê-la no contexto de um silogismo dedutivo (primeiro assentar as premissas teóricas, depois as hipóteses testadas, para chegar às conclusões), quando, muitas vezes, a tese ou dissertação não adota exatamente essa estrutura lógica.

\section{"Que Evidências Ihe Convém Aduzir Para Sua Afirmação?"}

Quem toma a iniciativa do ato de fala assertivo e se dirige a um auditório racional, assume a obrigação de dizer por quê. E, na linha de tudo o que foi dito em seção central neste artigo, surge a terceira pergunta estruturante. Ela indaga por evidências racionais para o convencimento, mesmo que isso não signifique persuasão.

O conhecimento sistematizado mais prestigiado na produção de evidências é a pesquisa, seja ela teórica ou empírica. No segundo caso, tem-se observação direta, ainda que definida e analisada em um sentido, presumivelmente uma intencionalidade, e melhor será quando esta coincidir com a do próprio discurso proferido perante o auditório; noutros termos, quando se fizer uso argumentativo de evidências primárias e procuradas para o proferimento em exame. Isso é o que fazem as teses, dissertações e outros textos baseados em pesquisa do próprio autor. Não que o uso de fontes secundárias, freqüentes no estilo ensaio, não possa alcançar o convencimento com igual intensidade. Mas que, sabiamente, a comunidade preserva na pesquisa original, teórica ou empírica, sua especificidade social na produção de conhecimento. E passa a exigir tal habilidade dos entrantes, ou ali titulados.

Não há limites nem sistematização exaustiva para as estratégias de produção de evidência. Em seção anterior fez-se referência ao pensamento de Aristóteles 
e à obra de Perelman e Olbrechts-Tyteca. São, entre outros, esforços válidos, aos quais vale recorrer, porém que mais confirmam seus próprios limites. Porque a evidência é a plena elucidação do significado de uma fala em determinado contexto, e, por causa da variedade ilimitada de contextos construídos circunstancialmente ou supostos na comunicação, os significados de fala são incomensuráveis (Wittgenstein, 1996). Então cada orador-autor constrói livremente sua teia de argumentos, usando, dentro das regras da objetivação, quase-estratégias e lugares costumeiramente aceitos, ou, sob certo risco, outros novos.

Contudo a ciência normal (Kuhn) tem argumentos-padrão e limites relativamente estreitos para os novos. Alguns daqueles são claramente preferidos, por questões paradigmáticas, diz-se. Os manuais de metodologia de pesquisa, já quase uma especialidade e um campo próprio de competência, os catalogam, mais a partir da prática corrente do que dos horizontes da hermenêutica, da retórica, e mesmo de uma sã epistemologia (como a popperiana). Dentro de um paradigma epistemológico moderno, como se tentou caracterizar em seção anterior, eles encontram guarida, porque desenvolvem instrumental, chaves com as quais parecem supor - é possível abrir, com exclusividade, as portas da realidade, e conhecê-la algo como ela é. Os labirintos e as engenharias que constroem, no entanto, podem tornar-se, na fração de segundo da má compreensão de um estudante ou acadêmico, puras práticas formalistas. Só há uma saída para evitá-lo: entender o contexto de seu sentido argumentativo e, por isso, seus limites de uso, desmistificando, por conseqüência, aquelas práticas. Falta um contramanual de metodologia de pesquisa para fazê-lo...

Enfim, a pergunta-título desta seção se refere a que lhe convém; não por convocar o oportunismo ou a ideologia, mas por referir-se às convicções teóricas do autor e porque, no caso de argumentos de evidência empírica, tudo depende da viabilidade prática da coleta e análise dos dados. Cada pesquisador, pelo tempo e recursos de que dispõe, o saberá.

\section{Conclusão}

Este artigo argumentou a favor de uma concepção e forma que, na estruturação de dissertações, teses e artigos propostos à comunidade acadêmica, considera preferível, até mesmo ao convencional estilo relatório de pesquisa. Este se compõe invariavelmente de Introdução, Fundamentação (ou Referencial) Teórica, Metodologia, Resultados ou Análise de Dados e Conclusões. Os autores de tais textos, sobretudo estudantes, muitas vezes se confundem e se perdem, porque não relacionam sua tarefa com um ato comunicativo bem definido, agarran- 
do-se, por segurança, à dimensão formal de seu texto e à estrutura convencionada pelos manuais como científica.

De qualquer forma, aquelas peças acadêmicas não deveriam ser, como muitos aparentam, artefatos empírico-conceituais, ou certa obra de arte literária, burilada com esmero para deleite próprio ou demonstração de competência a público de gostos semelhantes. Não se pretende generalizar, mas o formalismo ronda aqueles produtos acadêmicos!

Propõe-se, consoante o sentido pragmático tradicional, que se concebam teses, dissertações e artigos acadêmicos como discursos de retórica argumentativa. Isso não é estranho à ciência; pelo contrário, está na iniciativa e na apresentação de resultados das pesquisas, teóricas ou empíricas, que entram na vida acadêmica como atos de comunicação de caráter assertivo. Nesse contexto, os procedimentos metodológicos são estratégias que visam a produzir evidências e só alcançam a unidade do texto como argumentos em favor do que inicialmente este enuncia.

Nessa perspectiva, a estrutura básica do discurso teria apenas três partes: o estado (ou estabelecimento) da questão, a argumentação e a conclusão (que volta ao estado da questão). Cabe desdobrar os elementos dessa estrutura, de forma didática.

No estado da questão, o acordo com o auditório

. exigirá que o texto anuncie, de início, claramente, e que justifique aquilo para que se faz ou a que se propõe o discurso: sua motivação e seu objetivo;

- igualmente bem expresso deve ficar o objeto do acordo, que é uma ou mais proposições (ou hipóteses);

. esta ou estas, porém, devem ser precedidas da problematização de fatos ou idéias, justamente o que os/as torna objeto de discussão, dissenso e possível acordo. Nessa problematização surgem e devem ser explicitados:

. o contexto (histórico, teórico, político-institucional, social etc.) pertinente;

. o objeto real de interesse;

. o seu enfoque interpretativo (ou foco);

elementos que caracterizam as proposições e, com elas, todo o discurso.

A argumentação, centro do discurso retórico, exige 
. não necessariamente de início ou em bloco, a explicitação dos conceitos-chaves de que lança mão o orador, quer em

- argumentos teóricos, de elaboração própria ou de outros autores de sua tradição, quer em

- argumentos empíricos que haja desenvolvido no campo problematizado; de qualquer forma, a argumentação é a própria justificação das proposições objeto de acordo.

As conclusões não podem ser outras que a própria recapitulação das proposições iniciais, agora na linguagem e no detalhe que os argumentos teóricos e empíricos já permitem.

A adoção da abordagem pragmática que define teses, dissertações e artigos acadêmicos como discursos de retórica argumentativa permitiria tornar desnecessárias e até formais as atuais polarizações metodológicas, e, além disso, abrigar no campo da Administração, em igualdade de condições quanto à estruturação, textos de áreas técnicas (Finanças e Ciências Contábeis, por exemplo) e de áreas teóricas (Teoria Organizacional, Comportamento, Estratégia, Sistemas de Informação, Marketing etc.).

Cada vez mais a ciência contemporânea é pluralista e, felizmente, nossa prática acadêmica tende a ser grande arena de argumentos, consensos e dissensos, em que se reconhece, como valor, a dialética racional. Nesse espaço social, o objeto em disputa não é mais o certo, o definitivo, o verdadeiro, mas o válido, o verossímil, o defensável; enfim, o preferível. Urge que tal prática comunicativa reconstrua sua própria coerência, a partir de nova prática metodológica de estruturação de textos científicos!

\section{Not A}

${ }^{1}$ Referindo-se a estes dois aspectos, Guba e Lincoln (1999, p. 106) usam as expressões inglesas emic (insider's view) e etic (outsider's view). O Dicionário Houaiss da Língua Portuguesa (2001, p. 1122, 1271) registra as palavras êmico ("relativo à descrição de unidades lingüísticas em termos de sua função dentro do sistema ao qual pertencem”) e ético ("relativo à descrição das unidades lingüísticas consideradas em termos físicos, sem correlação com sua função no sistema da língua”), apenas no sentido original, sem nenhum derivado, como o usado pelos autores acima. Por isso, evitando neologismo algo sofisticado, preferiram-se aqui expressões mais usuais. 
ReferênCIAs Bibliográficas

\section{ALVESSON, M.;}

DEETZ, S.

Teoria crítica e abordagens pósmodernas para estudos organizacionais. In: CLEGG, S.; HARDY, C; NORD, W. R. (Orgs.). Handbook de estudos organizacionais. São Paulo: Atlas, 1999. v. 1. p. 227-266.

AUSTIN, J. L.

Quando o dizer é fazer. Porto Alegre: Artes Médicas, 1990.

BABBIE, E. R.

The practice of social research. 2. ed. Belmont, CA: Wadsworth, 1979.

BARCHELAR, G.

La formation de l'esprit scientifique. Paris: J. Vrin, 1972.

BARZUN, J.;

GRAFF, H. F.

The modern researcher. 5 . ed. New York: Harcourt Brace Javanovich, 1992.

BURRELL, G.; MORGAN, G.

Sociological paradigms and organizational analysis. London: Heinemann, 1979.
CHALMERS, A.

O que é ciência, afinal? São Paulo: Brasiliense, 1993.

DEMO, P.

Metodologia científica em ciências sociais. 3. ed. São Paulo: Atlas, 1995.

Conhecimento moderno: sobre ética e intervenção do conhecimento. Petrópolis: Vozes, 1997.

DENZIN, N. K.;

LINCOLN, I. S.

Handbook of qualitative research. London: Sage Publications, 1994.

DICIONÁRIO HUAISS DA LÍNGUA PORTUGUESA.

Rio de Janeiro: Objetiva, 2001.

GEERTZ, C.

O saber local. 2. ed. Petrópolis: Vozes, 1999.

GROSS, A.

The rethoric of science. Cambridge, MA: HUP, 1996. 
GUBA, E.;

LINCOLN, I.

Competing paradigms in qualitative research. In: DENZIN, N. K.; LINCOLN, I. S. Handbook of qualitative research. London: Sage Publications, 1999.

HABERMAS, J.

Consciência moral e agir comunicativo. Rio de Janeiro: Tempo Brasileiro, 1989.

Pensamento pós-metafísico. Rio de Janeiro: Tempo Brasileiro, 1990.

KNORR-CETINA, K.

The manufacture of knowledge: on essay on the constructivist and contextual nature of science. Oxford: Pergamon, 1981.

LATOUR, B.;

FABBRI, P.

Rhétorique de la science. Actes de la recherche en sciences sociales, n.13, p. 81-95, 1977.

LYOTARD, J.-F.

The postmodern condition: a report on knowledge. Minneapolis: University of Minnesota, 1997.

MILES, M. B.;

HUBERMAN, A. M.

Qualitative data analysis. London: Sage Publications, 1984.
MORIN, E.

Ciência com consciência. Rio de Janeiro: Bertrand Brasil, 1996.

PERELMAN, C.;

OLBRECHTS-TYTECA, L.

Rhétorique et philosophie: pour une théorie de l'argumentation en philosophie. Paris: PUF, 1952.

Tratado da argumentação: a nova retórica. São Paulo: Martins Fontes, 1999.

POPPER, K.

Replies to my critics. In: SCHILPP, P. The philosophy of Karl Popper. La Salle: Open Court, 1974. v. 2. p. 961-1197.

Conhecimento objetivo. Belo Horizonte: Itatiaia, 1975.

QUINE, W. V.

Word and object. Cambridge, MA: MIT, 1960.

\section{SANTOS, B. DE S.}

A crítica da razão indolente: contra o desperdício da experiência. São Paulo: Cortez, 2000.

SEARLE, J.

Mente, linguagem e sociedade: filosofia no mundo real. Rio de Janeiro: Rocco, 2000.

WITTGENSTEIN, L.

Investigações filosóficas. São

Paulo: Nova Cultura, 1996. 